\title{
Unmodifiable Clinicopathological Risk Factors of Shoulder Tip or Subcostal Pain after Laparoscopic Appendectomy
}

Bomi Kim, M.D., Jungbin Kim, M.D., Inseok Park, M.D., Hyunjin Cho, M.D., Geumhee Gwak, Ph.D., Keun Ho Yang, Ph.D., Byung-Noe Bae, Ph.D., Kihwan Kim, Ph.D.

Department of General Surgery, Sanggye Paik Hospital, Inje University College of Medicine, Seoul, Korea

Purpose: Appendectomy, which comprises most benign intra-abdominal surgeries, is currently assisted by laparoscopy in most cases. However, many patients complain of postoperative shoulder or subcostal pain after laparoscopic surgery. In some cases, the pain lasts even several weeks after surgery. This study aimed to analyze unmodifiable clinicopathological factors of patients who underwent laparoscopic appendectomy and to minimize preoperative and postoperative discomfort.

Methods: Patients admitted for laparoscopic appendectomy for acute appendicitis with an American Society of Anesthesiology (ASA) grades I and II, and ages 12 70 years were enrolled in the study. Postoperative shoulder or subcostal pain was assessed using the visual analogue scale (VAS) for pain and analyzed with the clinicopathological factors of the patients, including age, sex, weight, height, body mass index (BMI), and abdominal circumference (AC) difference.

Results: Of the 124 patients, 40 complained of postoperative shoulder or subcostal pain with a VAS score of $\geq 4$. The risk of the postoperative shoulder or subcostal pain increased in women $(p=0.001)$. From a univariate analysis, the risk of postoperative shoulder or subcostal pain increased with lower height, weight and BMI ( $p=0.002, p=0.001, p=0.012)$ and with greater AC difference $(p=0.012)$. However, a multivariate analysis showed that lower weight was the only risk factor of postoperative pain ( $p=0.005)$.

Conclusion: The risk of postoperative shoulder or subcostal pain after laparoscopic appendectomy was significantly increased with lower weight.

Keywords: Appendectomy, Laparoscopic, Pneumoperitoneum, Shoulder pain
Received September 18, 2019

Revised 1st October 21, 2019

2nd November 5, 2019

3rd November 13, 2019

4th November 13, 2019

Accepted November 14, 2019

Corresponding author

Inseok Park

Department of General Surgery, Inje University Sanggye Paik Hospital, 1342 Dongil-ro, Nowon-gu, Seoul 01757, Korea

Tel: +82-2-950-1017

Fax: +82-2-950-1429

E-mail: S5507@paik.ac.kr ORCID:

https://orcid.org/0000-0002-6415-9307

This is an Open Access article distributed under the terms of the Creative Commons Attribution Non-Commercial License (http:// creativecommons.org/licenses/by-nc/4.0/) which permits unrestricted non-commercial use, distribution, and reproduction in any medium, provided the original work is properly cited.

Copyright (c) 2020 The Journal of Minimally Invasive Surgery. All rights reserved.

\section{INTRODUCTION}

Appendectomy is one of the most frequently performed surgical procedure. ${ }^{1}$ Although the open method was considered the treatment of choice for acute appendicitis, laparoscopic appendectomy has gained much popularity since $\mathrm{Semm}^{2}$ introduced the procedure and is widely performed nowadays., Compared with open appendectomy, several meta-analyses have confirmed that laparoscopic appendectomy has its efficiency and superiority in terms of less postoperative pain and faster return to daily activities with fewer wound complications. $^{5-7}$

During the laparoscopic procedure, a pneumoperitoneum at $12 \mathrm{mmHg}$ was induced with a short duration followed by carbon dioxide gas automatically regulated by a high-flow insufflator. Many patients complain of post-laparoscopic shoulder 
or subcostal pain. In some cases, the pain has been reported to last as long as 7 days or even 5 weeks after surgery. ${ }^{8-10}$ Its mechanism is commonly assumed to be overstretching of the diaphragmatic muscle fibers due to the pressure of a pneumoperitoneum or increasing intra-abdominal pressure by $\mathrm{CO}_{2}$, which causes diaphragmatic irritation. ${ }^{11,12}$ However, under the same surgical settings, the frequency and intensity of the postoperative shoulder or subcostal pain are considered to differ among patients according to their innate clinicopathological factors. This study aimed to analyze the clinicopathological factors of patients who underwent laparoscopic appendectomy and suggest measures for minimizing preoperative and postoperative discomfort.

\section{MATERIALS AND METHODS}

The study protocol was approved by the Inje University Sanggye Paik Hospital Institutional Review Board (IRB; SGP IRB NO.2015-07-007), and informed consent was obtained from all the patients before participation. From October 2015 to September 2016, all consecutive patients who underwent emergency or elective laparoscopic appendectomy were recruited for this prospective study. The primary end point of our study was the relationship between postoperative pain and the clinicopathological characteristics of patients. A sample size of 124 patients was estimated to obtain a power of $90 \%$ with $\alpha$ of 0.05 , $\beta$ of 0.10 (correlation coefficient, 0.3 ), and dropout rate of $10 \%$.

The inclusion criteria were as follows: (1) patients with ASA grade 1 or 2, and (2) patients aged between 12 and 70 years. The exclusion criteria ruled out the patients who were unable to provide informed consent, and those with a previous abdominal surgery, medication history of analgesics including NSAIDs, previous shoulder or subcostal pain before surgery, and pregnancy. Patients who required conversion to laparotomy and who had operative findings of appendiceal perforation with peritonitis or abscess that required drainage postoperatively were excluded from the analysis (Fig. 1).

Patients were asked preoperatively about the presence of shoulder or subcostal pain and again on postoperative days 1 and 2. If they had pain, they were asked to quantify it on a visual analogue scale (VAS) between 0 and 10 using a questionnaire. Pain management was deemed necessary with a minimum score of 4. Patients were divided into two groups, one with a VAS score of $\leq 4$ and one with a VAS score of $\geq 4$. All patients who had postoperative pain were administered intravenous ketorolac tromethamine (Ketolan ${ }^{\circledR} 30 \mathrm{mg}$ ) or tramadol hydrochloride (Tridol ${ }^{\boxplus} 50 \mathrm{mg}$ ) every 8 hours from the operation date to postoperative day 2 .

In all the patients, $12 \mathrm{mmHg}$ of $\mathrm{CO}_{2}$ was insufflated dur- ing surgery. The patients' clinicopathological characteristics included age, sex, body weight, height, pneumoperitoneum on abdominal radiography, and abdominal circumference (AC) difference before and after the surgery. The end-tidal $\mathrm{CO}_{2}\left(\mathrm{ETCO}_{2}\right)$ level was recorded according to end-expiratory $\mathrm{PaCO}_{2}$ level on mechanical ventilation monitoring. Vital sign, blood test results, including hemoglobin, white blood cell count, and C-reactive protein level were recorded preoperatively and postoperatively for all the patients. Postoperative pain and associated problems such as nausea and vomiting were also recorded.

The categorical variables included sex, ASA grade, and postoperative pneumoperitoneum on plain radiography. The relationship between these variables and postoperative subcostal or shoulder pain was analyzed using the Pearson $\chi^{2}$ test. Numerical data including age, height, weight, BMI, AC difference, operation time, and $\mathrm{ETCO}_{2}$, and were analyzed using analysis of variance with multivariate logistic regression analysis. Statistical significance was defined as a $p$ value of $<0.05$.

\section{RESULTS}

Of the 124 patients who participated in this study, 61 were male and 63 were female, with a sex ratio of 1:1.03. The age range was 12 64 years, with a median of 35 years. The height ranged from 143 to $186 \mathrm{~cm}$, with a median of $164 \mathrm{~cm}$. The weight ranged from 35 to $120.4 \mathrm{~kg}$, with a median of $64 \mathrm{~kg}$. The median BMI was $23.4 \mathrm{~kg} / \mathrm{m}^{2}$ (range, $15.4 \sim 38.4 \mathrm{~kg} / \mathrm{m}^{2}$ ). Changes in abdominal circumference after the surgery ranged from -1 to $3 \mathrm{~cm}$, with a median of $1 \mathrm{~cm}$. The surgery duration ranged from 12 to 130 minutes, with a median value of

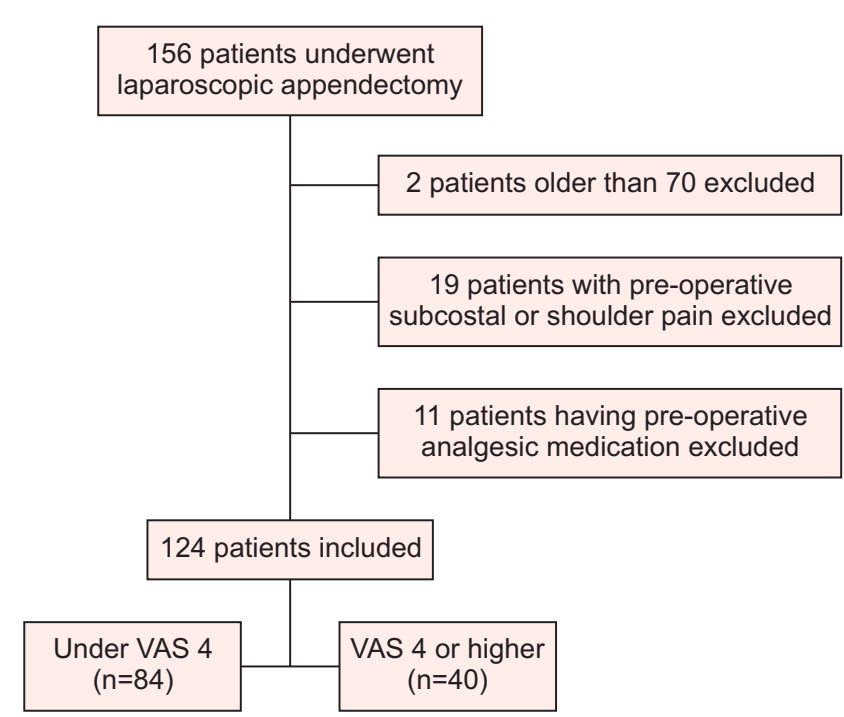

Fig. 1. Flowchart on patient selection. VAS $=$ Visual analogue scale. 
50 minutes. Postoperative abdominal radiography revealed to have no pneumoperitoneum in 92 patients (74\%). $\mathrm{ETCO}_{2}$ ranged from 25 to $45 \mathrm{mmHg}$ with a median value of 33 $\mathrm{mmHg}$. Forty patients complained of pain with a VAS score of $\geq 4$ at some point postoperatively (32.3\%; Table 1): Of the 124 patients, $87(70.2 \%)$ had postoperative pain with a VAS score of $<4$ on day 1; of these 87 patients, 3 (3.4\%) complained of postoperative shoulder or subcostal pain with a VAS score of $\geq 4$ on day 2. Thirty-seven patients (29.8\%) had postoperative pain with a VAS score of $\geq 4$ on day 1; of these, 20 (54.1\%) had pain with a VAS score of $<4$ and 17 out of 37 (45.9\%) still complained of pain with a VAS score of $\geq 4$ on day 2 .

Patients were controlled by routine IV analgesic medications, with ketorolac tromethamine (Ketolan ${ }^{\circledR} 30 \mathrm{mg}$ ) being administered every 8 hours. For 40 patients who complained of postoperative shoulder or subcostal pain with a VAS score of $\geq 4$, tramadol hydrochloride (Tridol ${ }^{\circledR} 50 \mathrm{mg}$ ) was injected intravenously as needed. All participants were discharged from the hospital after 2 nights and 3 days.

Table 1. Clinicopathologic characteristics and demographics of patients

\begin{tabular}{|c|c|}
\hline Characteristic & \\
\hline \multicolumn{2}{|l|}{ Sex: $n(\%)$} \\
\hline Male & $61(49.2)$ \\
\hline Female & $63(50.8)$ \\
\hline Age: years (range) & $35(12 \sim 76)$ \\
\hline \multicolumn{2}{|l|}{ ASA grade: $n(\%)$} \\
\hline 1 & $97(78.2)$ \\
\hline$\|$ & $27(21.8)$ \\
\hline Height: cm (range) & $164(143 \sim 186)$ \\
\hline Weight: cm (range) & $63(35 \sim 120.4)$ \\
\hline BMI: $\mathrm{m}^{2} / \mathrm{kg}$ (range) & $23.4(15.4 \sim 38.4)$ \\
\hline AC difference: cm (range) & $1(-1.0 \sim 3.0)$ \\
\hline Duration of operation: minutes (range) & $50(12 \sim 130)$ \\
\hline \multicolumn{2}{|l|}{ Pneumoperitoneum on X-ray: $n(\%)$} \\
\hline $1+1$ & $92(74.2)$ \\
\hline$(-)$ & $32(25.8)$ \\
\hline $\mathrm{ETCO}_{2}: \mathrm{mmHg}$ (range) & $33(25 \sim 45)$ \\
\hline \multicolumn{2}{|l|}{ VAS: $n(\%)$} \\
\hline Under VAS 4 & $84(67.7)$ \\
\hline VAS 4 or higher & 40 (32.3) \\
\hline
\end{tabular}

Values are presented as the median range or number $(\%)$. ASA $=$ American Society of Anesthesiology; $\mathrm{AC}=$ Abdominal circumference; $\mathrm{BMI}=$ Body mass index; $\mathrm{ETCO}_{2}=$ End-Tidal $\mathrm{CO}_{2} ;$ VAS = Visual analogue scale.
According to the study results, the risk of postoperative shoulder or subcostal pain is higher among women than among men ( $p=0.001$; Table 2). Patients who did not show pneumoperitoneum on postoperative abdominal radiography

Table 2. Comparison between categorical factors and post-operative pain

\begin{tabular}{lcccc}
\hline \multicolumn{1}{c}{ Characteristics } & $\begin{array}{c}\text { Under } \\
\text { VAS } 4 \\
(\mathbf{n}=84)\end{array}$ & $\begin{array}{c}\text { VAS } 4 \\
\text { or higher } \\
(\mathbf{n}=40)\end{array}$ & $p$ value & OR \\
Sex & & & 0.001 & 0.258 \\
Male & $50(82.0)$ & $11(18.0)$ & & \\
Female & $34(54.0)$ & $29(46.0)$ & & \\
ASA grade & & & 0.028 & 0.295 \\
I & $61(62.9)$ & $36(37.1)$ & & \\
II & $23(85.2)$ & $4(14.8)$ & & \\
Pneumoperitoneum & & & 0.003 & 5.830 \\
(-) & $55(59.8)$ & $37(40.2)$ & & \\
I+) & $29(90.6)$ & $3(9.4)$ & & \\
\hline
\end{tabular}

Values are presented as the number (\%). ASA = American Society of Anesthesiology; VAS = Visual analogue scale.

Table 3. Comparison between numerical variables and post-operative pain by univariate analysis

\begin{tabular}{lccc}
\hline \multicolumn{1}{c}{ Characteristics } & $\begin{array}{c}\text { Correlation } \\
\text { coefficient }\end{array}$ & $p$ value & 95\% Cl \\
\hline Age & -0.1005 & 0.2670 & $-0.2720 \sim 0.07723$ \\
Height & -0.2711 & 0.002 & $-0.4270 \sim-0.09958$ \\
Weight & -0.2949 & 0.001 & $-0.4479 \sim-0.1251$ \\
BMl & -0.2257 & 0.012 & $-0.3866 \sim-0.05138$ \\
AC difference & 0.1883 & 0.011 & $0.01238 \sim 0.3529$ \\
Duration of operation & -0.01975 & 0.8277 & $-0.1954 \sim 0.1571$ \\
\hline
\end{tabular}

$\mathrm{AC}=$ Abdominal circumference; $\mathrm{BMI}=$ Body mass index .

Table 4. Comparison between numerical variables and post-operative pain by multivariate analysis

\begin{tabular}{|lccc|}
\hline Characteristics & OR & $95 \% \mathrm{Cl}$ & $p$ value \\
\hline Height & 1.019 & $0.778 \sim 1.333$ & 0.893 \\
\hline Weight & 0.954 & $0.923 \sim 0.986$ & 0.005 \\
\hline BMI & 1.151 & $0.439 \sim 3.013$ & 0.775 \\
\hline AC difference & 1.540 & $0.979 \sim 2.429$ & 0.064 \\
\hline
\end{tabular}

$\mathrm{AC}=$ Abdominal circumference; $\mathrm{BMI}=$ Body mass index. 
were more likely to have postoperative pain ( $p=0.003$; Table 2). A univariate analysis showed that the risk of postoperative shoulder or subcostal pain increased with lower height, weight and BMI ( $p=0.002, p=0.001, p=0.012$, respectively) and greater AC difference ( $p=0.011$; Table 3$)$. However, a multivariate analysis showed that lower weight was the only risk factor of postoperative pain ( $p=0.005$; Table 4$)$.

\section{DISCUSSION}

Compared with open surgeries, laparoscopic appendectomies have relatively faster recovery, shorter admission duration, and faster return to daily activities. ${ }^{4-6}$ However, patients who have received laparoscopic appendectomies have complained of postoperative shoulder and subcostal pain. These pains occur 1 or 2 days after the procedure and last between 7 days to 5 weeks. In some cases, the shoulder or subcostal pain was reported to be greater in intensity than the incisional pain. ${ }^{13}$ According to Boonstra, ${ }^{14}$ VAS scores of 3.5 6.4 implied moderate pain with moderate interference with functioning. We defined a VAS score of 4 as the minimum pain that was necessary for pain management. In general, postoperative shoulder or subcostal pain is minimal, especially in laparoscopic appendectomy. However, in this study, 32.3\% of patients complained of postoperative pain with a VAS score of $\geq 4$. We excluded patients who had operative findings of perforated appendix or abscess, but patients were not otherwise divided according to the type of appendicitis as the final pathology (acute appendicitis with suppurative or gangrenous change) were not reported until approximately 7 days after the surgery.

Several studies have investigated the pathophysiology of the postoperative shoulder and subcostal pains after laparoscopic surgeries. The most accepted explanation states that insufflation of the abdominal cavity with carbon dioxide causes excessive stretching of the muscle fibers of the diaphragm, which causes stretch injury on the diaphragmatic nerves and leads to referred pain on the shoulder., ${ }^{4,815}$ A study by Shin in 2010 reported that respiratory volume, that is, the tidal volume for each respiration, increases with insufflation. Increased stretching of the abdominal cavity leads to increased stretching of the diaphragm, where the phrenic nerve is compressed, and the shoulder pain is exacerbated. ${ }^{16}$ One study reports that the abdominal wall curvature expands in the sagittal plane rather than in the transverse plane during laparoscopic appendectomy. This characteristic causes a significant diaphragmatic overstretching during insufflation. ${ }^{17}$ In this study, as direct measurement of the sagittal plane of the abdomen is impossible, the transverse plane was measured to indirectly measure changes in abdominal circumference after the surgery. We predicted that as the magnitude of abdominal cavity stretching increased, the postoperative abdominal circumference would increase. ${ }^{18,19}$ When the postoperative abdominal circumference was greater than the pre-operative circumference, the incidence rates of postoperative shoulder and subcostal pains were increased. This observation corroborates the fact that the pain is caused by diaphragmatic nerve damage secondary to excessive stretching (Table 3).

Relative muscle mass (\%) is widely known to decrease with age in the 30s. ${ }^{20,21}$ Initially, postoperative pain intensity was predicted to increase with increasing age because the decreased muscle mass predisposes the abdominal wall to overstretching. However, this theory was found statistically insignificant in this study (Table 2). Hence, we can infer that other clinicopathological factors, such as height, weight, and BMI play a role in determining the intensity of postoperative shoulder or subcostal pain.

Men are known to have more lean mass than women, and women are known to have more fat mass than men. Men are known to have accumulation of adipose tissue in the trunk and abdomen, while women have accumulation of adipose tissue in the hip and thigh. ${ }^{20,22}$ This study showed that the median body weights of the men and women were 74 and $55 \mathrm{~kg}$, respectively. The incidence of abdominal overstretching was relatively lower in the men than in the women, and the mean was predicted to have less-intense postoperative pain. Therefore, significant correlation between sex and pain intensity was observed in this study (Table 2).

When the patients were insufflated with identical $\mathrm{CO}_{2}$ pressure, higher incidence rates of postoperative shoulder and subcostal pains were observed in the patients with lower height, weight, or BMI. Abdominal stretching can be predicted to be higher in patients with lower BMI than in patients with higher BMI when insufflated with identical $\mathrm{CO}_{2}$ pressure.

Another theory states that the postoperative shoulder and subcostal pains are caused by the chemical irritation on the diaphragm due to the insufflation agent, $\mathrm{CO}_{2}$. ${ }^{23}$ Another study that investigated the correlation between residual $\mathrm{CO}_{2}$ gas volume and postoperative shoulder pain reported that patients who received gas drainage showed a significant decrease in pain intensity. ${ }^{24}$ In this study, the amount of residual $\mathrm{CO}_{2}$ gas volume was not measured because the patients did not have a drainage. The presence of pneumoperitoneum in patients was determined using abdominal radiography on postoperative day 1, and patients who did not show pneumoperitoneum were more likely to have postoperative pain ( $p=0.003$; Table 2). However, as the exact amount of pneumoperitoneum was not measured, quantification of insufflation through postoperative radiography would be necessary to explain the correlation between residual $\mathrm{CO}_{2}$ gas volume and postoperative shoulder or subcostal pain. In addition, the amount of $\mathrm{CO}_{2}$ gas insuf- 
flation, insufflation rate, size of the postoperative pneumoperitoneum, residual gas, and the operator's surgical technique should be further controlled for better results.

Correlation between the surgery duration and postoperative shoulder/subcostal pain was investigated. Although longer surgery duration was predicted to increase the incidence of postoperative shoulder/subcostal pain because it increases the time of overstretching of the abdominal cavity and exposure to $\mathrm{CO}_{2}$ gas irritation, no significant correlation was confirmed (Table 3). The median durations of the laparoscopic appendectomy were 50 and 45 minutes in the two groups, respectively, which are insufficient to trigger postoperative pain. ${ }^{25}$

This study investigated the correlation between postoperative shoulder or subcostal pain and unmodifiable factors such as height, weight, and BMI. On the basis of the results of the patient's physical characteristics shown in this study, whether the patient will experience postoperative pain could be predicted. In the future, the insufflation pressure could be adjusted on the basis of the patient's clinicopathological characteristics; thereby, the incidence of postoperative shoulder or subcostal pain will be reduced.

\section{CONCLUSION}

The risk of postoperative shoulder or subcostal pain after laparoscopic appendectomy was significantly increased with lower weight.

\section{ORCID}

Bomi Kim, https://orcid.org/0000-0002-0672-585X Jungbin Kim, https://orcid.org/0000-0001-5839-619X Inseok Park, https://orcid.org/0000-0002-6415-9307 Hyunjin Cho, https://orcid.org/0000-0001-9158-3288 Geumhee Gwak, https://orcid.org/0000-0002-7910-1052 Keun Ho Yang, https://orcid.org/0000-0003-1039-4093 Byung-Noe Bae, https://orcid.org/0000-0002-5542-5626 Kihwan Kim, https://orcid.org/0000-0002-2882-4816

\section{AUTHORS' CONTRIBUTIONS}

Conceptualization: Inseok Park, Bomi Kim. Formal analysis: Inseok Park. Methodology: Jungbin Kim, Hyunjin Cho. Writing-original draft: Bomi Kim, Inseok Park, Keun Ho Yang. Writing-review and editing: Geumhee Gwak, ByungNoe Bae, Kihwan Kim.

\section{CONFLICT OF INTEREST}

None.

\section{FUNDING}

None.

\section{ACKNOWLEDGMENTS}

None.

\section{REFERENCES}

1) Dai L, Shuai J. Laparoscopic versus open appendectomy in adults and children: A meta-analysis of randomized controlled trials. United European Gastroenterol J 2017;5:542-553.

2) Semm K. Endoscopic appendectomy. Endoscopy 1983;15:59-64.

3) Guller U, Hervey S, Purves H, et al. Laparoscopic versus open appendectomy: outcomes comparison based on a large administrative database. Ann Surg 2004;239:43-52.

4) Tzovaras G, Baloyiannis I, Kouritas V, et al. Laparoscopic versus open appendectomy in men: a prospective randomized trial. Surg Endosc 2010;24:2987-2992.

5) Ignacio RC, Burke R, Spencer D, Bissell C, Dorsainvil C, Lucha PA. Laparoscopic versus open appendectomy: what is the real difference? Results of a prospective randomized double-blinded trial. Surg Endosc 2004;18:334-337.

6) Chung RS, Rowland DY, Li P, Diaz J. A meta-analysis of randomized controlled trials of laparoscopic versus conventional appendectomy. Am J Surg 1999;177:250-256.

7) Garbutt JM, Soper NJ, Shannon WD, Botero A, Littenberg B. Meta-analysis of randomized controlled trials comparing laparoscopic and open appendectomy. Surg Laparosc Endosc 1999;9:17-26.

8) Shin HY, Kim SH, Lee YJ, Kim DK. The effect of mechanical ventilation tidal volume during pneumoperitoneum on shoulder pain after a laparoscopic appendectomy. Surg Endosc 2010;24: 2002-2007.

9) Alexander JI, Hull MG. Abdominal pain after laparoscopy: the value of a gas drain. Br J Obstet Gynaecol 1987;94:267-269.

10) Chamberlain G. The recovery of gases insufflated at laparoscopy. Br J Obstet Gynaecol 1984;91:367-370.

11) Mouton WG, Bessell JR, Otten KT, Maddern GJ. Pain after laparoscopy. Surg Endosc 1999;13:445-448.

12) Berberoğlu M, Dilek ON, Ercan F, Kati I, Ozmen M. The effect of $\mathrm{CO} 2$ insufflation rate on the postlaparoscopic shoulder pain. J Laparoendosc Adv Surg Tech A 1998;8:273-277.

13) Dixon JB, Reuben Y, Halket C, O’Brien PE. Shoulder pain is a common problem following laparoscopic adjustable gastric band surgery. Obes Surg 2005;15:1111-1117.

14) Boonstra AM, Schiphorst Preuper HR, Balk GA, Stewart RE. Cutoff points for mild, moderate, and severe pain on the visual analogue scale for pain in patients with chronic musculoskeletal pain. Pain 2014;155:2545-2550. 
15) Bradley WG, Daroff RB, Fenichel GM, Jankovic J. Diagnosis of neurological disease. In: Bradley WG, Daroff RB, Fenichel GM, Jankovic J, editors. Neurology in clinical practice : Principles of diagnosis management. 4th ed. Philadelphia, PA: ButterworthHeinemann; 2004. p.3-5.

16) Sarli L, Costi R, Sansebastiano G, Trivelli M, Roncoroni L. Prospective randomized trial of low-pressure pneumoperitoneum for reduction of shoulder-tip pain following laparoscopy. Br J Surg 2000;87:1161-1165.

17) Song C, Alijani A, Frank T, Hanna GB, Cuschieri A. Mechanical properties of the human abdominal wall measured in vivo during insufflation for laparoscopic surgery. Surg Endosc 2006;20:987990.

18) Tuvayanon W, Toskulkao T, Asdornwised U, Akaraviputh TJTTJoS. Factors impacting readiness to discharge time from recovery room after laparoscopic cholecystectomy. THAI J Surg 2011;32: 53-59.

19) Ure BM, Niewold TA, Bax NMA, Ham M, van der Zee DC, Essen GJ. Peritoneal, systemic, and distant organ inflammatory responses are reduced by a laparoscopic approach and carbon dioxide versus air. Surg Endosc 2002;16:836-842.
20) Janssen I, Heymsfield SB, Wang ZM, Ross R. Skeletal muscle mass and distribution in 468 men and women aged $18-88$ yr. J Appl Physiol (1985) 2000;89:81-88.

21) Wu R, Delahunt E, Ditroilo M, Lowery M, De Vito G. Effects of age and sex on neuromuscular-mechanical determinants of muscle strength. Age (Dordr) 2016;38:57-57.

22) Bredella MA. Sex differences in body composition In: MauvaisJarvis F, editor. Sex and gender factors affecting metabolic homeostasis, diabetes and obesity. Cham(Switzerland): Springer; 2017. p.9-27.

23) Aitola P, Airo I, Kaukinen S, Ylitalo P. Comparison of $\mathrm{N} 2 \mathrm{O}$ and $\mathrm{CO} 2$ pneumoperitoneums during laparoscopic cholecystectomy with special reference to postoperative pain. Surg Laparosc Endosc 1998;8:140-144.

24) Abbott J, Hawe J, Srivastava P, Hunter D, Garry R. Intraperitoneal gas drain to reduce pain after laparoscopy: randomized masked trial. Obstet Gynecol 2001;98:97-100.

25) Hua J, Gong J, Yao L, Zhou B, Song Z. Low-pressure versus standard-pressure pneumoperitoneum for laparoscopic cholecystectomy: a systematic review and meta-analysis. Am J Surg 2014; 208:143-150. 